\title{
Effect of Combined Therapy with Hyperbaric Oxygen and Antioxidant on Infarct Volume after Permanent Focal Cerebral Ischemia
}

\author{
G. ACKA ${ }^{1}$, A. SEN ${ }^{2}$, Z. CANAKCI ${ }^{3}$, S. YILDIZ ${ }^{4}$, A. AKIN ${ }^{2}$, G. UZUN ${ }^{4}$, \\ H. CERMIK ${ }^{5}$, I. YILDIRIM ${ }^{6}$, S. KOKPINAR ${ }^{7}$
}

${ }^{I}$ Department of Neurosurgery, Mersin University Medical Faculty, Mersin, ${ }^{2}$ Department of Aerospace Medicine, ${ }^{3}$ Neurosurgery Clinic, Turkish Air Force Eskisehir Hospital, Eskisehir, ${ }^{4}$ Departments of Underwater and Hyperbaric Medicine, ${ }^{5}$ Departments of Pathology, ${ }^{6}$ Departments of General Surgery, GMMA Haydarpasa Training Hospital, Istanbul, ${ }^{7}$ Departments of Underwater and Hyperbaric Medicine, Istanbul University, Istanbul, Turkey

Received November 21, 2005

Accepted March 27, 2006

On-line available June 22, 2006

\begin{abstract}
Summary
The aim of the present study was to evaluate the efficiency of combination of hyperbaric oxygen (HBO) and an antioxidant on permanent focal cerebral ischemia. Male Wistar rats underwent permanent middle cerebral artery occlusion (MCAO). Then, animals were randomly assigned to one of four groups: the control group $(n=9)$ received no treatment, HBO group $(\mathrm{n}=9)$ was treated for 90 min at 2.5 absolute atmosphere for 3 days, the U-74389G group $(\mathrm{n}=8)$ received single $\mathrm{U}-74389 \mathrm{G}$ injection $(3 \mathrm{mg} / \mathrm{kg})$, the $\mathrm{HBO}+\mathrm{U}-74389 \mathrm{G}$ group $(\mathrm{n}=8)$ received both $\mathrm{HBO}$ and $\mathrm{U}-74389 \mathrm{G}$ treatments. Treatments were initiated within the first $10 \mathrm{~min}$ after MCAO. After 3 days, the infarct volumes in rat brains were measured. The infarct ratios were $25.6 \pm 6.5 \%$ for the control group, $21.9 \pm 6.4 \%$ for the HBO group, $15.7 \pm 5.7 \%$ for U-74389G group and $12.5 \pm 3.8 \%$ for HBO + U74389G group. The infarct volumes were significantly reduced in rats treated with $\mathrm{U}-74389 \mathrm{G}(p<0.05)$ and combination therapy $(p<0.05)$. HBO failed to reduce infarct volume significantly. We concluded that 1) U-74389G is more beneficial than HBO on permanent MCAO in rats, and 2) a combined therapy failed to significantly improve infarct volume more than either single treatment.
\end{abstract}

Key words

Cerebral ischemia $\bullet$ Permanent $\bullet$ Hyperbaric oxygenation $\bullet$ U-74389G

\section{Introduction}

Ischemic stroke is a clinical condition that develops in connection with transient or permanent blocking of a single intracranial artery. Since the brain tissue is highly sensitive to hypoxia, restoring tissue oxygenation is one of the main strategies in acute stroke treatment. Hyperbaric oxygen (HBO) has been used as a primary or adjunctive therapy in several experimental and clinical stroke studies (Nighoghossian et al. 1995, 
Sunami et al. 2000, Rusyniak et al. 2003, Schabitz et al. 2004, Günther et al. 2005, Hjelde et al. 2002, Lou et al. 2004). However, the use of HBO in ischemic stroke treatment remains controversial (Zhang et al. 2005).

Most of the ischemic stroke cases are caused by permanent occlusion of cerebral arteries (Christou et al. 2000). Some studies reported that single administration of HBO reduces infarct volume after permanent middle cerebral artery occlusion (MCAO) (Sunami et al. 2000, Schabitz et al. 2004, Günther et al. 2005), while others failed to show a beneficial effect (Hjelde et al. 2002, Lou et al. 2004). Repetitive HBO treatment is recommended for optimum dose of HBO treatments (Rogatsky et al. 2003, Jain 2004). A recent study showed that single HBO does, but repetitive $\mathrm{HBO}$ does not, reduce infarct volume after permanent MCAO (Günther et al. 2005). Although underlying mechanisms are not clear, reactive oxygen species (ROS) induced by oxygen treatment under high pressure may be responsible for this discrepancy (Günther et al. 2005). Repetitive HBO treatments may cause excessive generation of ROS (Benedetti et al. 2004, Topal et al. 2004). Neuronal cell membranes are very sensitive to ROS induced damage due to very rich polyunsaturated fatty acid composition. Antioxidant supplementation has been shown to decrease HBO induced oxidative stress (Etlik et al. 1997, Alleva et al. 2005). The combination of HBO and antioxidants in acute stroke treatment has not been studied before.

This preliminary study was conducted in order to evaluate the efficacy of combination of hyperbaric oxygen (HBO) and of an antioxidant on permanent focal cerebral ischemia. Lazaroid (U-74389G, 16-desmethyl tirilazad mesylate) was used for antioxidant supplementation. Lazaroids are potent inhibitors of ROSinduced lipid peroxidation (Hall et al. 1994). The primary aim of this study was to assess the infarct volumes in rat brains three days after permanent MCAO. The effect of HBO, U-74389G and combination of both treatments on infarct volume were therefore evaluated.

\section{Methods}

All experimental procedures were performed in accordance with the National Institutes of Health guidelines and approved by the local ethics committee.

\section{Experimental groups}

A total of 34 male Wistar rats weighing 250 to $350 \mathrm{~g}$ were used. During experiments, the animals were housed in cages with free access to food and water under controlled temperature and 12-hour light/dark cycles for at least one week. The animals were randomly assigned to one of four groups; Control group ( $n=9$ ) received no treatment, HBO group $(n=9)$ received repetitive HBO treatments, $\mathrm{U}-74389 \mathrm{G}$ group $(\mathrm{n}=8)$ received a single U-74389G treatment, HBO + U-74389G group $(n=8)$ received both $\mathrm{U}-74389 \mathrm{G}$ and $\mathrm{HBO}$ treatments.

\section{Surgical Procedure}

Anesthesia was provided by the use of intramuscular ketamine hydrochloride $(60 \mathrm{mg} / \mathrm{kg})$. During surgery, rectal temperature was maintained at $37^{\circ} \mathrm{C}$ with a heating pad. Middle cerebral artery (MCA) occlusion was performed as described by Bederson et al. (1986). Briefly, the right MCA was exposed under an operating microscope by a transtemporal approach. After partly excising the temporalis muscle, a $3 \mathrm{~mm}$ burr hole was drilled $2-3 \mathrm{~mm}$ rostral at the fusion of the zygoma and the squamosal bone. The dura was opened and retracted to expose the MCA above the rhinal fissure. The MCA was cauterized with a microbipolar coagulator from the olfactory nerve to the inferior cerebral vein, and then cut. The temporal muscle and skin were closed in layers.

\section{$H B O$ and $U-74389 G$ treatments}

Animals in the HBO and HBO + U-74389G groups were placed in a steel animal hyperbaric chamber during the initial $10 \mathrm{~min}$ after MCAO. Before pressurization, $100 \%$ medical oxygen was flushed through the chamber for $10 \mathrm{~min}$ to displace ambient air. Oxygen pressure was then increased slowly and reached 2.5 ATA in $10 \mathrm{~min}$. The chamber was ventilated during HBO therapy to avoid carbon dioxide accumulation. After 90 min at 2.5 ATA the chamber was decompressed to the normal atmospheric pressure in $10 \mathrm{~min}$. Subsequent HBO and U-74389G treatments were applied 24 and $48 \mathrm{~h}$ after initial HBO treatment. Animals in the $\mathrm{U}-74389 \mathrm{G}$ and $\mathrm{HBO}+\mathrm{U}-74389 \mathrm{G}$ groups received an intraperitoneal injection of U-74389 in a dose of $3 \mathrm{mg} / \mathrm{kg}$ 10 min after MCAO.

\section{Evaluation of infarct area}

After 3 days, the animals were reanesthetized with ketamine hydrochloride and decapitated. The brains were swiftly extracted and placed into tissue cutters; each brain was divided into six $2-\mathrm{mm}$ coronal sections. The sections were incubated at $37^{\circ} \mathrm{C}$ degrees for $30 \mathrm{~min}$ in a $2 \%$ solution of 2,3,5-triphenyltetrazolium chloride (TTC) 


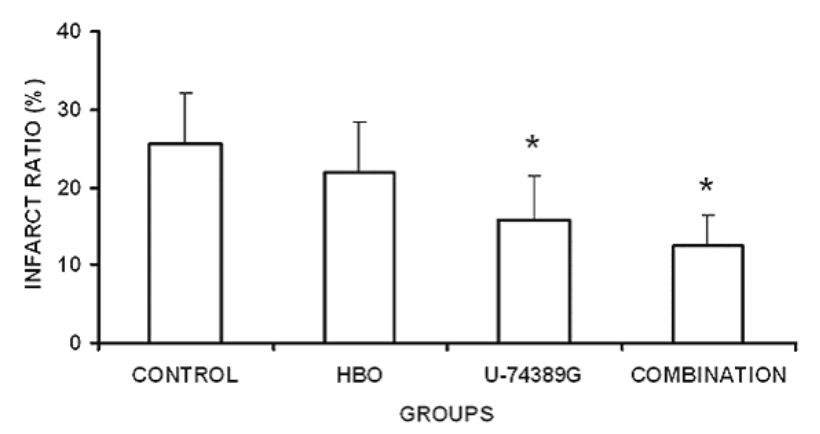

Fig. 1. Infarct ratios in the studied groups three days after permanent middle cerebral artery occlusion. HBO; hyperbaric oxygen, Combination; HBO+U-74389G. Data are expressed as mean $\pm \mathrm{SD}$. $* \mathrm{p}<0.05$ vs. control group (one-way ANOVA followed by Bonferroni test)

(Sigma Chemical Co., USA) in $0.9 \% \mathrm{NaCl}$. The sections were placed in $10 \%$ formalin for $24 \mathrm{~h}$ fixation. At the end of this process, brain infarct areas remained as unstained white areas. The brain slices were photographed with a digital camera. Total area of the hemisphere and infarct areas were calculated by using an image analysis program (OSIRIS Imaging Software, version 4.18, University Hospital of Geneva, Switzerland). The percentage of infarction (infarct ratio) was calculated by dividing the infarct area by the total area of the ipsilateral hemisphere. The analysis was carried out under blinded conditions.

\section{Statistical Analysis}

The results were expressed as mean \pm S.D. The differences between groups were assessed using one-way analysis of variance (ANOVA), followed by Bonferroni test for multiple comparisons. A value of $p<0.05$ was considered statistically significant.

\section{Results}

Total infarct ratios were $25.5 \pm 6.4 \%$ for the control group, $21.9 \pm 6.4 \%$ for HBO group, $15.7 \pm 5.9 \%$ for $\mathrm{U}-74389 \mathrm{G}$ group and $12.5 \pm 3.8 \%$ for the $\mathrm{HBO}+\mathrm{U}-$ 74389G group (Fig. 1). The infarct volumes were significantly reduced in rats treated with U-74389G $(p<0.05)$ and combination therapy $(p<0.05)$. Repetitive HBO treatment failed to reduce the total infarct volume significantly.

\section{Discussion}

Lazaroids (synthetic 21-aminosteroids) are potent inhibitors of ROS induced lipid peroxidation (Hall et al. 1994). U-74389G provides both antioxidant and anti-apoptotic effects (Zhang et al. 1998). U-74389G also leads to a visible protective effect on brain edema and blood-brain barrier defects in ischemia-reperfusion induced brain injury in rats (Durmaz et al. 2003). U-74389G prevents the reduction of total and free sulphydryl groups, superoxide dismutase and glutathione reductase activities, and decreases thiobarbituric acidreactive substances (Farbiszewski et al. 1994). Previous studies demonstrated that both multiple and single administration of U-74389G significantly attenuates neuronal damage after cerebral ischemia (Lee et al.1996, Tseng et al. 1997, Zhang et al. 1998, Durmaz et al. 2003). The time of $\mathrm{U}-74389 \mathrm{G}$ administration is also important. Zhang et al. (1998) showed that neuroprotective effects of U-74389G are more apparent when the drug is given at the beginning of the focal cerebral ischemia. However, Lee et al. (1996) showed that $\mathrm{U}-74389 \mathrm{G}$ is effective in global cerebral ischemia when it was administered before or $30 \mathrm{~min}$ after the ischemic period. In clinical settings, it is not likely to predict who will have a stroke and to start drug therapy before the initiation of cerebral ischemia. In our study, animals received a single i.p. dose of U-74389G after the beginning of the ischemic period; U-74389G was highly effective in reducing infarct volume. This is the first study to evaluate U-74389G in permanent MCAO. Park and Hall (1994) studied the effects of a different lazaroid, $\mathrm{U}-74006 \mathrm{~F}(3.0 \mathrm{mg} / \mathrm{kg})$, in permanent MCAO. The infarct volume and neurological deficit score was reduced in rats treated with U-74006F (Park and Hall 1994).

The effect of $\mathrm{HBO}$ on permanent cerebral ischemia is controversial. In animal models, HBO provided a beneficial outcome by increasing oxygen supply to the ischemic brain tissue (Sunami et al. 2000, Schabitz et al. 2004, Günther et al. 2005). However, in some studies HBO failed to demonstrate any beneficial effect on permanent focal cerebral ischemia (Hjelde et al. 2002, Lou et al. 2004). The timing of HBO treatments and infarct volume evaluation as well as HBO protocols vary among these studies. Most of the experimental studies have used a single $\mathrm{HBO}$ treatment regime in permanent MCAO (Zhang et al. 2005). There is only one article reporting repetitive $\mathrm{HBO}$ treatments in a permanent MCAO model (Günther et al. 2005). They demonstrated that single $\mathrm{HBO}$ had an effect, but repetitive $\mathrm{HBO}$ did not reduce infarct volume in permanent MCAO (Günther et al. 2005). In our study repetitive $\mathrm{HBO}$ did not reduce cerebral infarct volume. 
As we know, this is the first study evaluating the effect of combined therapy with $\mathrm{HBO}$ and an antioxidant on permanent MCAO as well as showing the beneficial effect of U-74389G on permanent focal cerebral ischemia. The combined therapy with $\mathrm{HBO}$ and U-74389G did not reduce infarct volume significantly compared to single treatments with either $\mathrm{HBO}$ or U-74389G. This may be due to the fact that U-74389G saved most of the damaged tissue alone and therefore the combination of both treatments failed to improve the results.

There are limitations in our study. The first is that the neurological scores of rats after permanent focal cerebral ischemia were not evaluated; therefore we do not know the clinical relevance of our results. The second is that on pathological examination only the infarct ratio was calculated and a detailed histopathological evaluation of the infarct area and ischemic penumbra was not performed.

In conclusion, our study showed that U-74389G is more beneficial than $\mathrm{HBO}$ on permanent $\mathrm{MCAO}$ in rats with respect to the infarct volume. HBO and U-74389G combination failed to improve significantly infarct volume more than each of the treatments alone. Although this negative result observed in the present study, we believe that further studies are needed to clearly evaluate the therapeutic potential of combination of different HBO protocols with different antioxidants.

\section{References}

ALlEVA R, NASOLE E, DI DONATO F, BORGHI B, NEUZIL J, TOMASETTI M: Alpha-lipoic acid supplementation inhibits oxidative damage, accelerating chronic wound healing in patients undergoing hyperbaric oxygen therapy. Biochem Biophys Res Commun 333: 404-410, 2005.

BEDERSON JB, PITTS LH, TSUJI M, NISHIMURA MC, DAVIS RL, BARTKOWSKI H: Rat middle cerebral artery occlusion: evaluation of the model and development of a neurologic examination. Stroke 17: 472-476, 1986.

BENEDETTI S, LAMORGESE A, PIERSANTELli M, PAGLIARANI S, BENVENUTI F, CANESTRARI F: Oxidative stress and antioxidant status in patients undergoing prolonged exposure to hyperbaric oxygen. Clin Biochem 37: 312-317, 2004.

CHRISTOU I, ALEXANDROV AV, BURGIN WS, WOJNER AW, FELBERG RA, MALKOFF M, GROTTA JC: Timing of recanalization after tissue plasminogen activator therapy determined by transcranial doppler correlates with clinical recovery from ischemic stroke. Stroke 31: 1812-1816, 2000.

DURMAZ R, ERTILAV K, AKYUZ F, KANBAK G, BILDIRICI K, TEL E: Lazaroid U-74389G attenuates edema in rat brain subjected to post-ischemic reperfusion injury. J Neurol Sci 215: 87-93, 2003.

ETLIK O, TOMUR A, DUNDAR K, ERDEM A, GUNDOGAN NU: The effect of antioxidant vitamins E and C on lipoperoxidation of erythrocyte membranes during hyperbaric oxygenation. J Basic Clin Physiol Pharmacol 8: 269-277, 1997.

FARBISZEWSKI R, CHWIECKO M, USTYMOWICZ J: The 21-aminosteroid U-74389G protects the antioxidant enzymes in the ischemia/reperfusion-induced rat brain damage. Eur J Pharmacol 270: 263-265, 1994.

GÜNTHER A, KÜPPERS-TIEDT L, SCHNEIDER PM, KUNERT I, BERROUSCHOT J, SCHNEIDER D, ROSSNER S: Reduced infarct volume and differential effects on glial cell activation after hyperbaric oxygen treatment in rat permanent focal cerebral ischaemia. Eur J Neurosci 21: 3189-3194, 2005.

HALL ED, MCCALL JM, MEANS ED: Therapeutic potential of the lazaroids (21-aminosteroids) in acute central nervous system trauma, ischemia and subarachnoid hemorrhage. Adv Pharmacol 28: 221-268, 1994.

HJELDE A, HJELSTUEN M, HARALDSETH O, MARTIN D, THOM R, BRUBAKK O: Hyperbaric oxygen and neutrophil accumulation/tissue damage during permanent focal cerebral ischaemia in rats. Eur J Appl Physiol 86: 401-405, 2002.

JAIN KK: Role of hyperbaric oxygen in the management of stroke. In: Textbook of Hyperbaric Medicine. JAIN KK (ed), Hogrefe \& Huber Publishers, Gottingen, Germany, 2004, pp 195-223.

LEE SH, KONDOH T, CAMARATA PJ, HEROS RC: Therapeutic time window for the 21-aminosteroid, U-74389G, in global cerebral ischemia. Neurosurgery 38: 517-522, 1996.

LOU M, ESCHENFELDER CC, HERDEGEN T, BRECHT S, DEUSCHL G: Therapeutic window for use of hyperbaric oxygenation in focal transient ischemia in rats. Stroke 35: 578-583, 2004. 
NIGHOGHOSSIAN N, TROUILLAS P, ADELEINE P, SALORD F: Hyperbaric oxygen in the treatment of acute ischemic stroke. A double-blind pilot study. Stroke 26: 1369-1372, 1995.

PARK CK, HALL ED: Dose-response analysis of the effect of 21-aminosteroid tirilazad mesylate (U-74006F) upon neurological outcome and ischemic brain damage in permanent focal cerebral ischemia. Brain Res 645: 157163, 1994.

ROGATSKY GG, SHIFRIN EG, MAYEVSKY A: Optimal dosing as a necessary condition for the efficacy of hyperbaric oxygen therapy in acute ischemic stroke: a critical review. Neurol Res 25: 95-98, 2003.

RUSYNIAK DE, KIRK MA, MAY JD, KAO LW, BRIZENDINE EJ, WELCH JL, CORDELL WH, ALONSO RJ: Hyperbaric oxygen therapy in acute ischemic stroke: results of the hyperbaric oxygen in acute ischemic stroke trial pilot study. Stroke 34: 571-574, 2003.

SCHABITZ WR, SCHADE H, HEILAND S, KOLLMAR R, BARDUTZKY J, HENNINGER N, MULLER H, CARL U, TOYOKUNI S, SOMMER C, SCHWAB S: Neuroprotection by hyperbaric oxygenation after experimental focal cerebral ischemia monitored by MRI. Stroke 35: 1175-1179, 2004.

SUNAMI K, TAKEDA Y, HASHIMOTO M, HIRAKAWA M: Hyperbaric oxygen reduces infarct volume in rats by increasing oxygen supply to the ischemic periphery. Crit Care Med 28: 2831-2836, 2000.

TOPAL T, OTER S, KORKMAZ A, SADIR S, METINYURT G, KORKMAZHAN ET, SERDAR MA, BILGIC H, REITER RJ: Exogenously administered and endogenously produced melatonin reduce hyperbaric oxygeninduced oxidative stress in rat lung. Life Sci 75: 461-467, 2004.

TSENG MT, CHAN SA, REID K, LYER V: Post-ischemic treatment with a lazaroid (U-74389G) prevents transient global ischemic damage in rat hippocampus. Neurol Res. 19: 431-434, 1997.

ZHANG F, ZHOU L, HUANG F, LIANG Y, ZHANG G: U-74389G suppresses lipid peroxidation and apoptosis following focal cerebral ischemia and reperfusion in rats. Chin Med J (Engl) 111: 838-841, 1998.

ZHANG JH, LO T, MYCHASKIW G, COLOHAN A: Mechanisms of hyperbaric oxygen and neuroprotection in stroke. Pathophysiology 12: 63-77, 2005.

\section{Corresponding author}

Senol Yildiz, GATA Haydarpasa Egt Hast. Sualti ve Hiperbarik Tip Servisi, 34668 Kadikoy, Istanbul, Turkey. E-mail: senoyildiz@yahoo.com 